\title{
Relleno facial con ácido hialurónico: técnica de pilares y malla de sustentación. Principios básicos para obtener una remodelación facial
} Facial filling with hyaloronic acid: pillars technique and supporting mesh. Basic principles to obtain a facial remodelling

\author{
Erazo, P.J .*, de Carvalho, A.C.**, Alexander, T.***, Ramos, M.**, Vianna, P.**
}

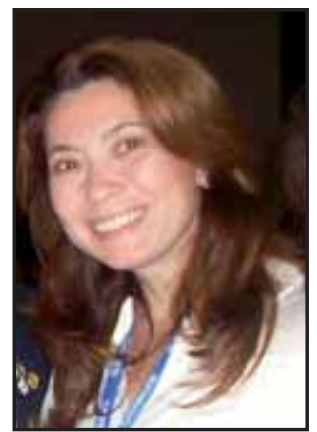

Erazo, P. J.
Presentamos dos técnicas de relleno facial utilizando ácido hialurónico y los resultados obtenidos con este método desarrollado por nosotros en base a los principios físicos de sustentación, para optimizar y racionalizar el material de relleno y mejorar los resultados, especialmente la relación costo-beneficio. Hacemos también una presentación general de los principios básicos para conseguir remodelar el tejido cutáneo empleando técnicas de relleno facial. Señalamos la importancia de la evaluación clínica para llegar a un buen diagnóstico, haciendo hincapié en los límites de selección del paciente y enumeramos los puntos importantes y éticos en el uso de materiales de relleno.

\begin{tabular}{|ll|}
\hline Palabras clave & $\begin{array}{l}\text { Ácido Hialurónico, Materiales de relle- } \\
\text { no, Remodelación facial, Técnica de }\end{array}$ \\
& Pilares. \\
Código numérico 266
\end{tabular}

We present two techniques of facial injectable resorbable filling, using hyaluronic acid (HA), and the different results obtained with both methods, based on physical principles of sustentation, intending to demonstrate how theese techniques can optimize and rationalize the use of the filling substance, contributing to enhance the results and cost-benefit relation.

We also make a general presentation of the basic principles that remodel the cutaneous tissue using facial filling methods, as well as the importance of the clinical evaluation to achieve a fine diagnostic, emphasizing the limits when selecting the patient, listing the important and ethical points related to the use of facial filling procedures.

$\begin{array}{ll}\text { Key words } & \begin{array}{l}\text { Hyaluronic Acid, Dermal Filler, Facial } \\ \text { remodeling, Pillar technique. }\end{array} \\ \text { Numeral Gode } & 266\end{array}$




\section{Introducción}

Las arrugas son el signo más evidente del envejecimiento facial; son depresiones dermo-epidérmicas, causadas principalmente por el sol (fotoenvejecimiento), por el envejecimiento intrínseco y la influencia de factores como: fuerza gravitacional, movimientos musculares repetidos de la mímica, desorganización de las fibras colágenas y elásticas y por pérdida progresiva de glicosaminoglicanos (1-3).

En la actualidad, existen diversos métodos de tratamiento que deben ser indicados de acuerdo al grado y tipo de envejecimiento del paciente, utilizando para ello las diferentes clasificaciones descritas en la literatura (Fitzpatrick, Glogau) (3-5).

En la cara, y de cuerdo con el grado de envejecimiento, podemos encontrar: líneas, arrugas, pliegues, surcos, hipercromías, hipocromías, flacidez, lesiones premalignas y malignas, todas ellas propias del envejecimiento, que pueden confluir y formar signos complejos de difícil tratamiento (5-8).

\section{Evaluación del envejecimiento}

La clasificación de Glogau continúa siendo de gran utilidad para el diagnostico de envejecimiento (Tipos I, II, III, IV) (4-9), pero dado que actualmente los pacientes emplean cada vez más métodos preventivos, con frecuencia no aparentan la edad cronológica que realmente tienen. Por tanto, en la práctica no deberíamos diagnosticar el envejecimiento por la edad, sino que sería correcto en toda evaluación clínica hacerlo en relación a las alteraciones que cada individuo presenta.

En todo tratamiento estético, el objetivo es la reestructuración del rostro, mejorando los llamados triángulos de la juventud (ángulo abierto de la pared lateral orbitaría, malar y definición del contorno mandibular) (4-7).

Para las arrugas superficiales indicamos métodos exfoliativos y todo aquel procedimiento que aumente el espesor de la epidermis y que estimule la organización de los fibroblastos en la dermis.

Para las arrugas profundas, de manera general, existe una combinación entre procedimientos quirúrgicos y técnicas de relleno, utilizándose estos últimos bien en forma profunda (grasa, dermis, hidroxiapatita,) o superficial o regeneradora (Ac. hialurónico, Ac. poliláctico, Ac. mandélico) $(6,7)$.

En el tercio medio de la cara es donde se encuentra el mayor número de grupos musculares que sufren la acción de la gravedad, y es también la región con mayor dificultad para mantenerse firme; como consecuencia se forman a este nivel los signos más graves de envejecimiento: arrugas, surcos pronunciados (sur- cos nasogenianos, comisura labial), alteraciones del contorno mandibular, alteraciones del labio (filtrum plano y largo, boca triste, arrugas verticales, alteraciones del bermellón) $(8,9)$. Es por esto que es en esta región donde se pueden realizar el mayor número de procedimientos estéticos quirúrgicos y no quirúrgicos y también, la región en la que está más indicado el empleo de materiales de relleno.

Cuando nos referimos a tratamiento y prevención, debemos dar mayor importancia a las áreas frontal y cervical, donde encontramos estructuras musculares únicas y superficiales, más accesibles de tratar en conjunto con la piel. El fortalecimiento y tonificación de estas regiones formará verdaderos pilares musculares (a modo de columnas que sustentan la cara), que otorgan mayor firmeza y soporte, especialmente al tercio medio, previniendo prematuramente el aparecimiento de los signos del envejecimiento (4-10).

El análisis semiológico de una región es importante para indicar sobre ella un tratamiento específico y un tratamiento preventivo. Se justifica el uso de rellenos de forma preventiva como sustentación de una área flácida y que en el futuro estará más deprimida o más elastósica, en pacientes jóvenes que tienen signos leves o medianos de envejecimiento (biotipo familiar). Al realizar prevención no está indicado utilizar materiales permanentes, pues no estaríamos cumpliendo con el concepto de tratamiento que es alimentar y nutrir el tejido que está envejeciendo, negando la oportunidad de que éste recobre y mantenga con naturalidad sus estructuras (3-9).

En esta última década se han descrito pocas técnicas de relleno $(3,11)$, pero sí que hemos apreciado la gran cantidad de compuestos y productos aparecidos en el mercado para llevar a cabo estos procedimientos con publicaciones que en su gran mayoría versan sobre experiencias con el uso de los diferentes materiales.

\section{Selección del paciente para relleno}

Los procedimientos basados en el uso de materiales de relleno están indicados en todo paciente, independientemente de su edad, que presente signos acentuados de envejecimiento en la región del labio superior, labio inferior, aplanamiento del labio superior con alteración de los pilares del filtrum, surcos nasogenianos (SNG) y comisuras labiales (CMS), con o sin alteraciones del contorno mandibular, especialmente en pacientes grados I, II y III de Glogau. En envejecimiento grados III y IV, cuando se indica cirugía, también puede ir acompañada del empleo de técnicas de relleno en estas mismas regiones.

Recomendamos realizar una maniobra bidigital (7) (colocando los dedos pulgar e índice en la región 
malar, y los mismos dedos de la mano contraria en el labio superior y mentón como indica la Fig.1), lo que nos permite verificar el estado de la zona y el punto de menor y mayor profundidad de los pliegues; además, nos indica la necesidad de menor o mayor cantidad de relleno a lo largo de la depresión. Esta región corresponde al punto más fuerte de envejecimiento facial (depresión de la piel), donde clínicamente existe la mayor necesidad de sustentación (punto crítico de envejecimiento) (Fig. 1).

\section{Límites en el empleo de materiales de relleno facial}

Están relacionados directamente con:

- Tipo de piel

- Grado de envejecimiento

- Tipo de arruga

- Flacidez cutánea

- Perfil del paciente (alimentación, actividad física, hábitos, profesión, enfermedades)

\section{-Edad}

Al existir varias combinaciones posibles de las alteraciones producidas por el envejecimiento, está indicado combinar las técnicas de relleno y/o los procedimientos quirúrgicos, peeling, láser, luz pulsada, dióxido de carbono, onda larga, radiofrecuencia, infrarrojos y otros procedimientos. Cada profesional debe tener la experiencia para evaluar al paciente e indicar uno $\mathrm{u}$ otro procedimiento.

En nuestra experiencia, los paciente con forma redonda de la cara y/ o piel oleosa o acneica suelen tener resultados más pobres o pueden tener complicaciones como: procesos inflamatorios más prolongados, peligro de infección por lesiones purulentas, o reactivación de quistes intradérmicos

\section{Aspectos éticos del uso de materiales de relleno facial}

Si consideramos desde todos los puntos de vista posibles un tratamiento efectivo, hasta ahora no existe material de relleno óptimo, que cumpla con todas las propiedades y características necesarias para serlo. Lo que existe son parámetros específicos que deben ser respetados y cumplidos cuando utilizamos un producto $(7,8)$, a saber:

- No alergénico

- No pirogénico

- No teratogénico

-Que no migre

-Que no precise test previo

-Que tenga una duración (entre 8 a 18 meses)

-Que no sea permanente.

Así al referirnos al mejor material de relleno facial posible, podremos decir que sería aquel que cumpliendo con los parámetros específicos descritos, con-

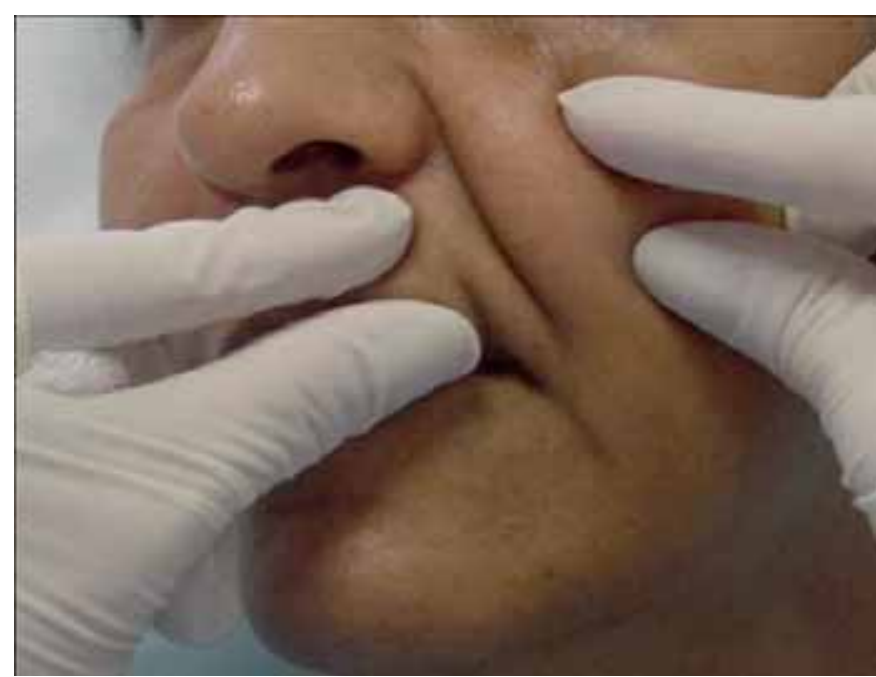

Fig. 1. Maniobra bidigital (punto de envejecimiento),demostrando las diferentes profundidades y alteraciones a lo largo de la depresión de la piel: nos auxilia para el inicio y el final del relleno consiguiendo una mejor sustentación de la zona. Permite cuantificar la cantidad de material a aplicar que será directamente proporcional a la depresión de la piel al realizar la maniobra.

sigue rellenar efectivamente la región deprimida, sea ésta una línea, una arruga o un surco y que además favorezca o no intervenga en el metabolismo cutáneo.

El material de relleno no puede producir alteraciones de movilidad de la musculatura mímica ni fibrosis graves. La mayoría de las veces observamos que los materiales permanentes alteran el movimiento de la región, limitando y alterando el proceso normal de envejecimiento. Generalmente, cuando realizamos ritidoplastias en pacientes en los que previamente se han utilizado este tipo de rellenos permanentes, se produce un proceso fibroso que siempre interfiere con el acto quirúrgico limitando la movilidad de las estructuras faciales.

Todas las precauciones posibles justifican un cuidado especial al tratar la región glabelar, especialmente cuando utilizamos compuestos permanentes, con características y propiedades específicas para ser aplicados en la profundidad del tejido (subcutáneo), por lo que pueden ser aplicados equivocadamente en vasos importantes, llegando a producir complicaciones desde leves a graves, con publicaciones incluso de casos de ceguera $(12,13)$.

Es importante recordar que de manera general, nuestro cuerpo tiene una reacción condicionada cuando se realiza un relleno sea éste reabsorbible, permanente o semipermanente; al inicio responderá al cuerpo extraño con inflamación transitoria y reacciones normales de defensa (Fig. 2), pero a partir de aquí, la respuesta dependerá del tipo de compuesto empleado y de las propiedades específicas de éste. Generalmente, los compuestos permanentes son más susceptibles de producir reacción inflamatoria crónica, con extrusión del compuesto en la mayoría de los 


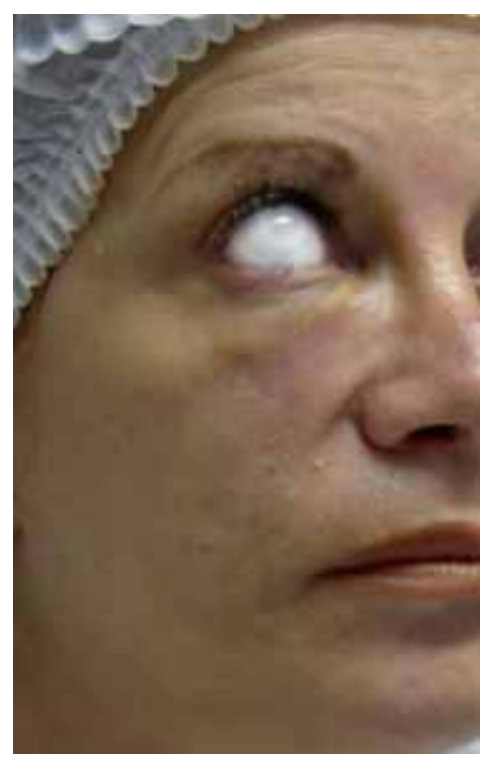

A
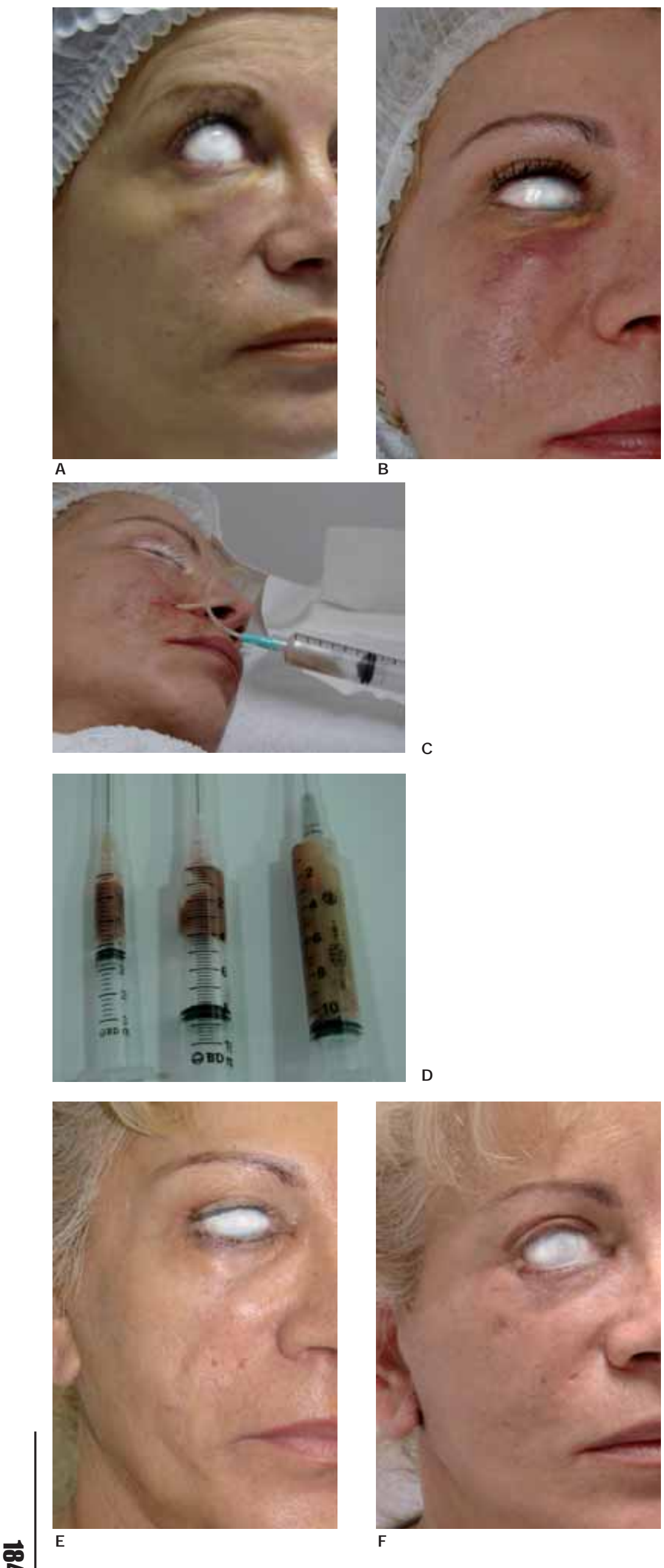

Fig. 2. A. Paciente con antecedentes de aplicación de material de relleno permamente (poliacrilamida: Aquamid $\left.{ }^{\circledR}\right)$; tiempo de evolución $+/-5$ años. Fibrosis en hemicara derecha con zonas de inflamación crónica; imposibilidad para la visión inferior, irritabilidad de la conjuntiva. C-D: fluctuación del área con extracción de líquido seroso y tejido graso fibronecrótico. E: resultado tras tratamiento y pre ritidoplastia F.- 2 meses postratamiento quirúrgico: ritidoplastia y retirada de tejido en párpado inferior y parcialmente en tercio medio, con injerto de grasa en depresión de hemicara. Ectropium en párpado inferior derecho pendiente de corrección.

casos y alteraciones desfigurantes en la piel, muchas veces con indicación de exéresis en bloque de piel y tejidos en todos sus planos, lo que puede dejar cicatrices inestéticas. Este tipo de reacciones cuando se usan compuestos permanentes pueden presentarse incluso después de varios meses o años de haberse aplicado el compuesto (18 a 36 meses). En casos más graves, cuando el compuesto es incompatible con el organismo, puede ocasionar alteraciones sistémicas graves (14,18), (Fig. 3-5).

Desde todo punto de vista ético, el paciente tiene derecho a ser informado sobre las ventajas y desventajas de cada producto y de manera especial del producto que estamos acostumbrados a utilizar y de cómo vamos a aplicarlo.

El costo del producto es un punto que nunca deberá ser colocado como principal ventaja en relación a la salud del paciente, sino que a la hora de elegir un material de relleno, debemos centrarnos en las ventajas y desventajas en relación a su acción.

$\mathrm{Si}$ seguimos las tendencia mundial, cuando el objetivo es tratar piel el material de relleno a emplear deberá ser reabsorbible y compatible con el organismo.

Al tratar alteraciones producidas por el envejecimiento, que por definición es un proceso fisiológico, dinámico y progresivo $(3,4,7,8)$, los materiales de relleno biodegradables serían los más compatibles con este concepto, pues hasta el momento no existe ningún tipo de procedimiento que lo detenga, sino métodos que minimizan y previenen sus signos. Pensamos por tanto que "el mejor material de relleno facial está directamente relacionado con la conciencia y conocimiento del ejecutor" (P. Erazo) $(4,7,8)$. 


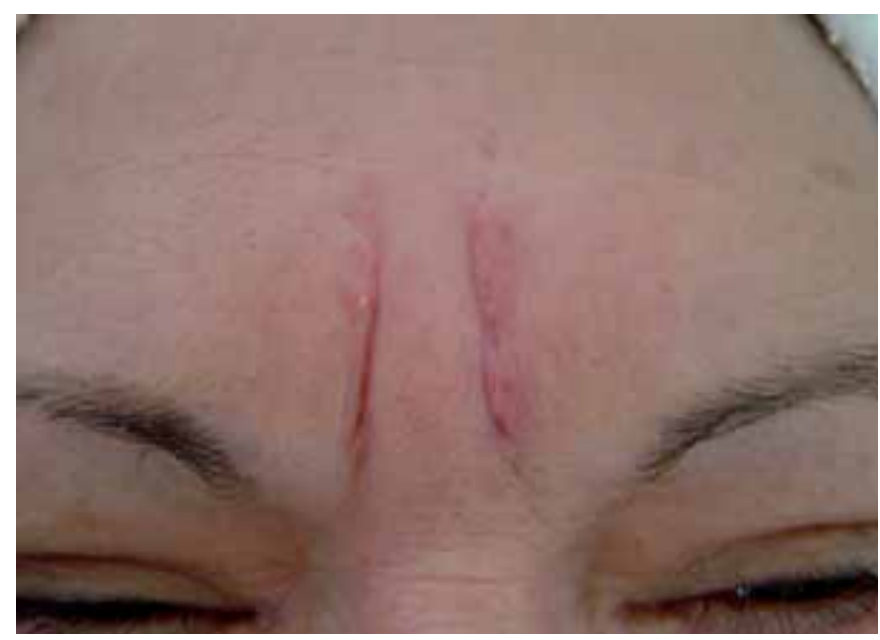

Fig. 3. Paciente con lesión superficial hipertrófica en región glabelar, reacción a cuerpo extraño con extrusión del material aplicado (antecedentes de aplicación de compuesto permanente de Metacrilato PMMA-Metacril $\left.{ }^{\circledR}\right)$.

\section{Acido Hialuronico}

En nuestra práctica habitual preferimos utilizar compuestos reabsorbibles y que sean compatibles con el organismo. El ácido hialurónico (AH) es un glicosaminoglicano constituido por residuos de ácido glucurónico y $\mathrm{N}$-acetilglucosamina; es abundante en todos los tejidos orgánicos de origen mesodérmico: humor vítreo, gelatina de Wharton del cordón umbilical, etc. $(1,2,11)$.

Los glicosaminoglicanos son polisacáridos complejos, moléculas muy ácidas, que poseen numerosas cargas negativas y atraen grandes cantidades de sodio y al mismo tiempo de agua; mediante este proceso aumenta la turgencia de la matriz extracelular $(1,2)$. Son los responsables de la capacidad de hidratación de la dermis y también de la turgencia y elasticidad de la piel.

El AH es diferente de otros polisacáridos, porque no tiene una forma definida, sino que forma mallas que son las encargadas de retener gran cantidad de agua (hidrofilia) $(1,2)$. Se extiende aleatoriamente ocupando un volumen muy grande debido a la repulsión electrostática de sus grupos carboxilo, motivo

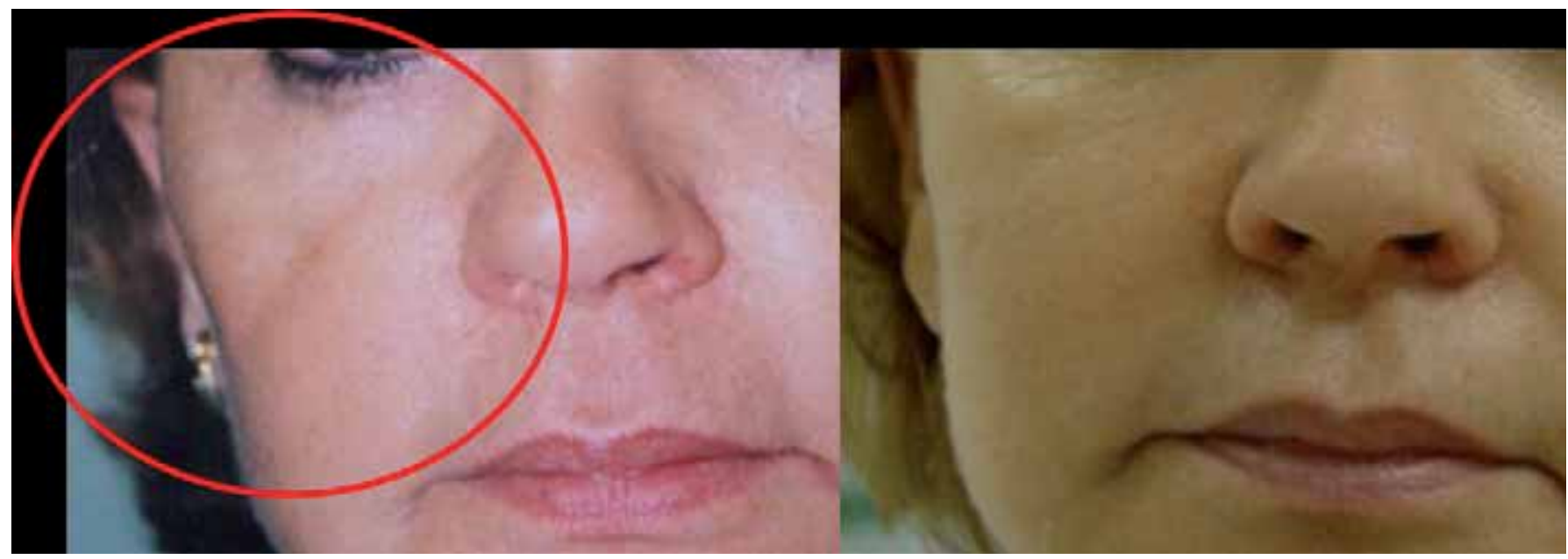

A.

B.

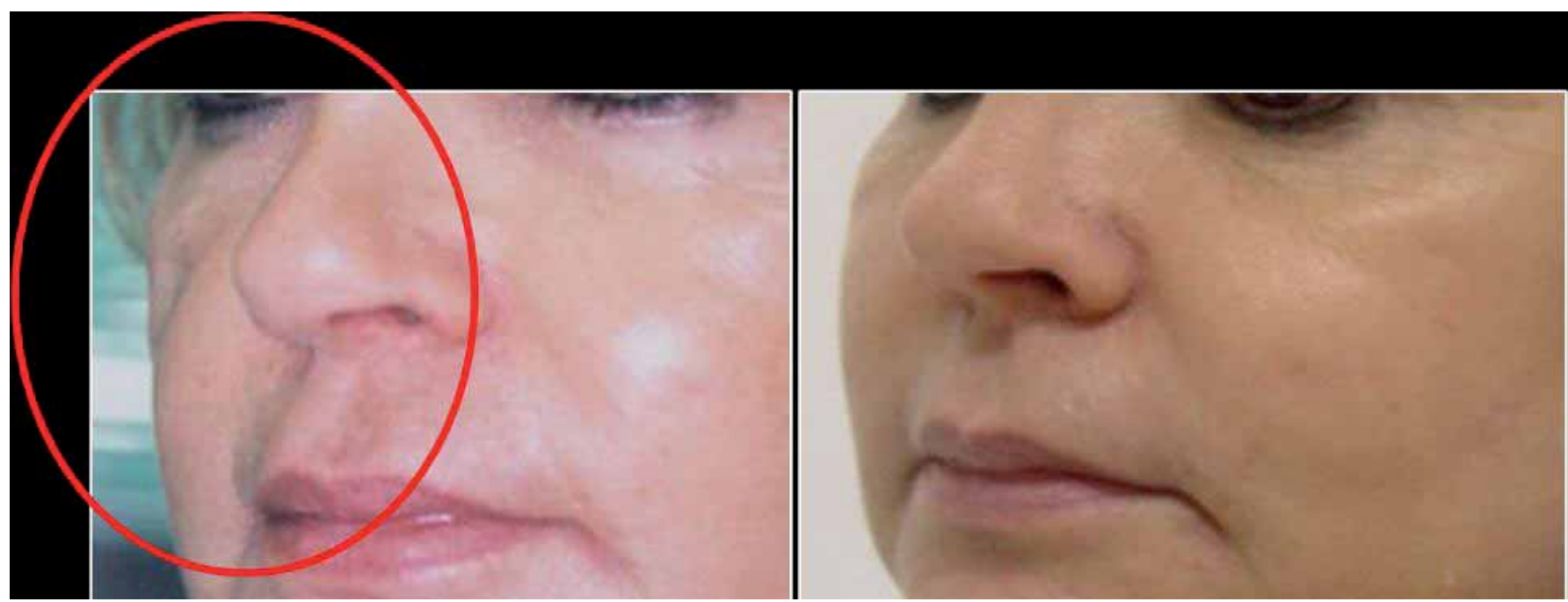

C.

D.

Fig. 4. A. Paciente de 52 años con complicación de PMMA + Corticoterapia. Depresión e hipopigmentación en región de malar B. Postratamiento a los 11 meses con Acido Hialurónico con técnica de pilares y relleno central. C. Vista de $3 / 4$ la misma paciente. D. Vista de $3 / 4$ post tratamiento con mejoría del contorno malar. 


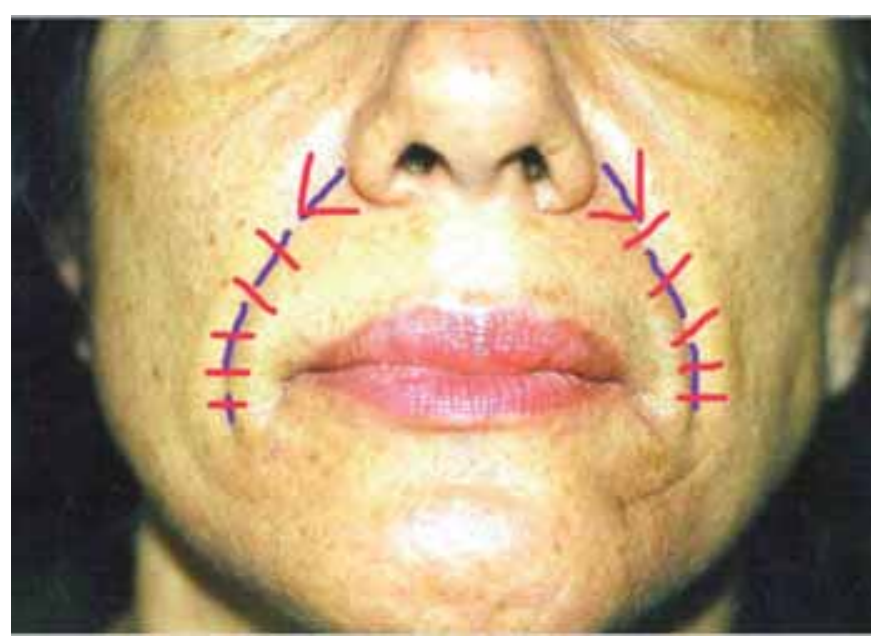

Fig. 5. Las líneas lilas representan la aplicación de AH por retroinyeccion en cantidad mínima. Paso 2 . En la región del asa nasal realizamos técnica en abanico. Paso 3. La líneas rojas representan la aplicación de AH perpendicular al surco: pilares.

por el cual clínicamente cada pilar de $\mathrm{AH}$ favorece la nutrición de los límites de la piel tratada.

Este polisacárido, puede ser sintetizado, purificado y estabilizado por métodos bioquímicos, dando origen a un producto final susceptible de ser empleado como material de relleno a nivel cutáneo. El origen no animal del producto facilita su uso debido a la casi inexistencia de reacciones alérgicas, no siendo necesario realizar pruebas de sensibilidad como las que había que realizar, por ejemplo, con el colágeno bovino purificado.

El AH se utiliza en su forma entrecruzada (Perfhecta ${ }^{\circledR}$, Belotero ${ }^{\circledR}$, Juvederm ${ }^{\circledR}$, Restylane ${ }^{\circledR}$ Teosyal ${ }^{\circledR}$, etc) como material de relleno (7), y está indicado para la corrección de líneas, arrugas, surcos, reborde de bermellón, aumento de labio, etc. En el aumento de malar, proyección del mentón y en la perfiloplastia de mandíbula, se utiliza en sus formas más acuosas aún en estudio, para intentar una supervivencia más larga del compuesto.

$\mathrm{Su}$ aplicación se hace en la dermis media y profunda y su periodo de absorción, de manera general, está entre los 6 y los 12 meses dependiendo de la viscosidad del producto y del método bioquímico de extracción; no necesariamente un compuesto es mejor que otro por la cantidad de miligramos de $\mathrm{AH}$ que contenga. Durante el período de tiempo que permanece en el organismo, activa y nutre las fibras de colágeno, mejorando clínicamente la flacidez y el tono de la piel (7) (Tabla I).

Cuando se utiliza AH en su forma lineal (Hyalsystem ${ }^{\circledR}$, Perfectha Meso ${ }^{\circledR}$, Restylane Vital $\left.{ }^{\circledR}\right)$, su indicación específica es para revitalización cutánea, recuperando porcentajes altos de ácido hialurónico endógeno en la dermis envejecida. En este caso se aplica en la dermis superficial y media, mediante técnica de pápula $(4,7)$.

En ambas formas de utilización, ya sea como relleno o como revitalización, podemos seguir diferentes métodos de aplicación : lineal, puntiforme, en malla, en criss-cross, pilares, etc (1-9).

\section{DESCRIPCIÓN DE LA TÉCNICA \\ Técnica de los Pilares aplicada para relleno facial}

Consiste en colocar varios pilares (como si fueran las pilastras que soportan un edificio) en la dermis, en sentido perpendicular (es decir contrario) al surco o arruga que queremos tratar, con la finalidad de dar sustentación y relleno al área utilizando la menor cantidad posible de producto $(3-5,7,8)$, siguiendo esta regla: donde hay una arruga o línea vertical, colocamos un pilar horizontal y viceversa (Fig. 6).

Realizamos el procedimiento con el paciente en decúbito supino a $45^{\circ}$, siempre con la asepsia requerida por todos los procedimientos de intradermoterapia, empleando par ello alcohol $70^{\circ}$ en gel o Clorhexidina. Recomendamos utilizar una crema anestésica 20 minutos antes del procedimiento (lidocaína tópica $4 \%$ ) para los rellenos superficiales y bloqueo del nervio infraorbitario y/ o mentoniano (4-8) para los rellenos profundos como: aumento de labio, reborde de bermellón, pilares del filtrum, etc.

\section{Relleno del Surco Nasogeniano}

Primero aplicamos el relleno con técnica de retroinyección con la finalidad de despegar la dermis; con el bisel hacia arriba, deslizamos la aguja como si fuera un túnel intradérmico en toda la longitud del surco hasta el asa nasal, realizando cada entrada a una distancia de unos $13 \mathrm{~mm}$ que corresponden más o menos a la longitud de la aguja. El sistema de relleno deberá iniciarse de abajo hacia arriba (ascendente con respecto a la arruga o pliegue) con la única finalidad de

Tabla I: La elección del tipo de AH se hará de acuerdo con la profundidad de la alteración cutánea y las particularidades de cada paciente

COMO DECIDIR EL TIPO DE AH A UTILIZAR

\begin{tabular}{lcccc} 
Acido Hialuronico $(\mathbf{A H})$ & Tipo de piel & Arrugas, surcos & Objetivo del tratamiento & Plano de aplicación \\
\hline $\begin{array}{l}\text { Viscoso normal } \\
+ \text { Viscoso-Partículas en gel }\end{array}$ & Fina & Superficiales Intermedias & Rellenar y Remodelar & Dermis intermedia \\
& Gruesa & Intermedias Profundas & Rellenar, Remodelar, Sustentar & Dermis Profunda \\
\hline
\end{tabular}




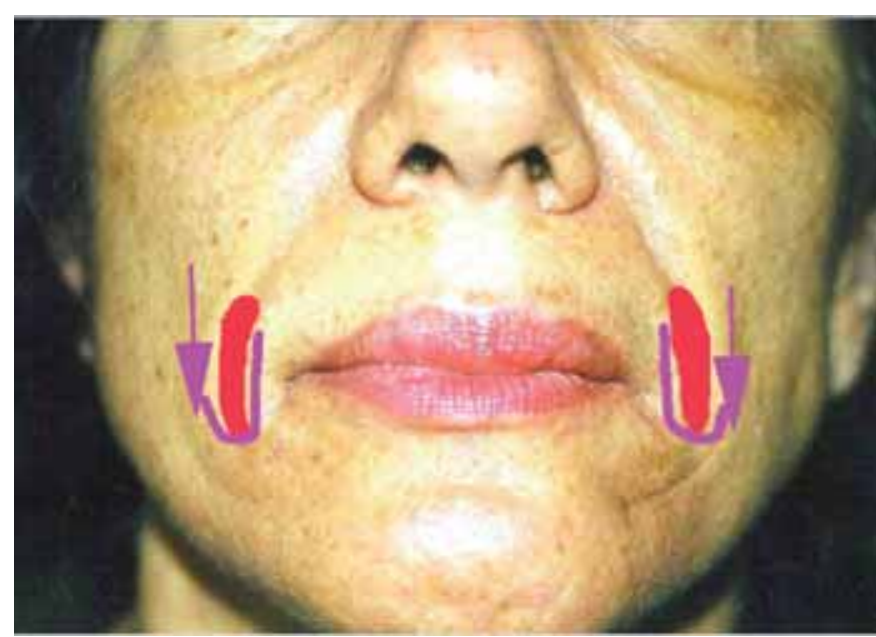

Fig. 6. Al realizar el análisis semiológico verificamos que si colocamos grandes cantidades en un surco profundo como el ejemplo de la foto, la paciente puede presentar un aspecto exagerado con apariencia de "bulldog", lo que generalmente sucede cuando queremos rellenar solamente una estructura.

que al introducir la aguja y depositar el relleno, éste no salga por el orificio de entrada de la punción anterior. En el área triangular del asa nasal y sin retirar la aguja, realizamos tres aplicaciones: superior medio e inferior, formando un triangulo con base en el asa nasal y vértice en el surco (técnica en abanico). Hace-
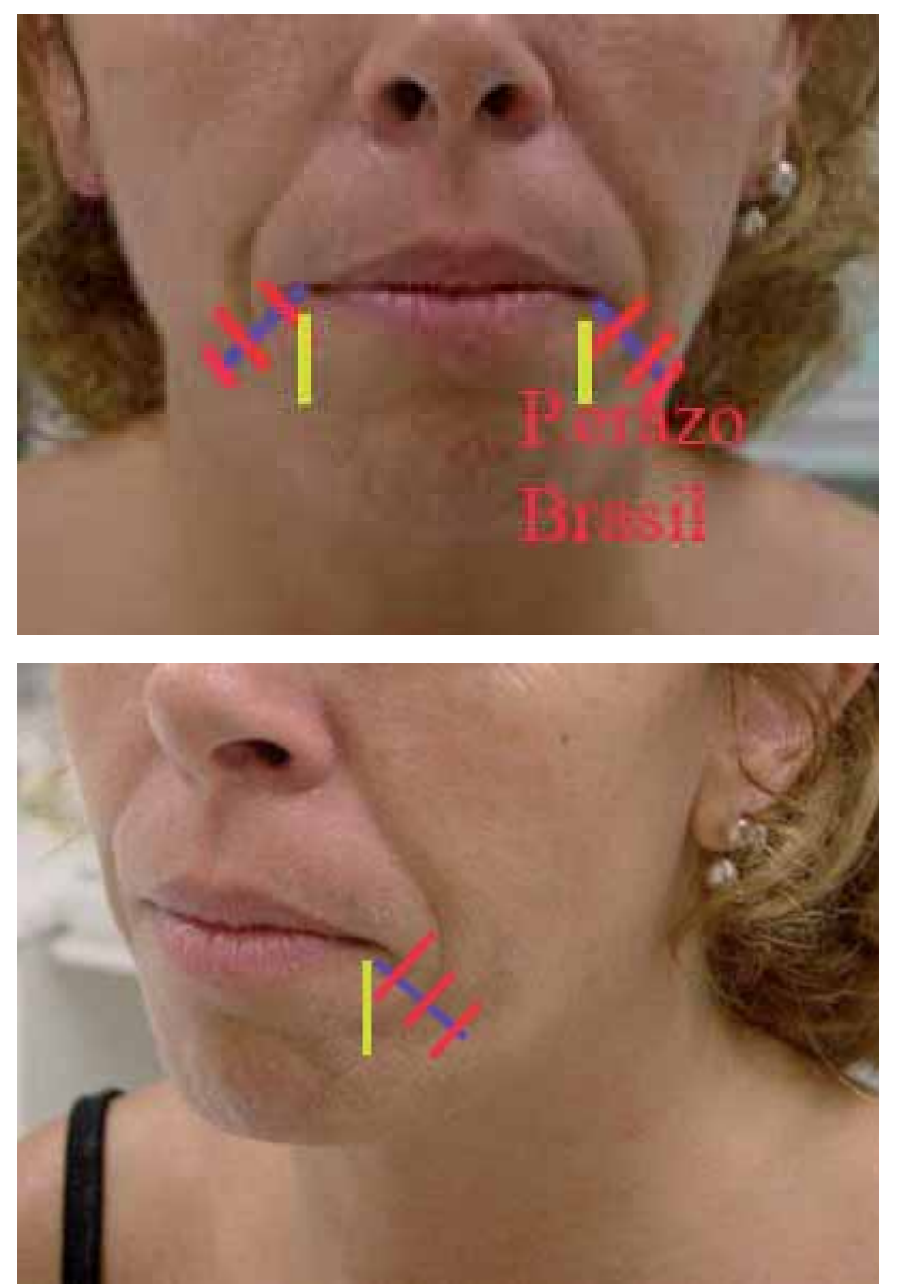

Fig. 7. En pacientes con "boca triste" se recomienda realizar una aplicación perpendicular a la comisura, como si fuera un pilar que sustentara el labio inferior, para poder levantar más la comisura. mos un relleno discreto buscando obtener un despegamiento del surco o de la arruga aplicando aproximadamente $1 \mathrm{ml}$ de producto en cada surco (Fig. 6).

\section{Confección de los Pilares}

Seguidamente realizamos de tres a cuatro aplicaciones en sentido horizontal, que atraviesan perpendicularmente el surco, a una distancia cada aplicación de 0.7 a $1 \mathrm{~cm}$ y que son los que hemos descrito como pilares (3-9). Para la confección de cada pilar utilizamos aproximadamente $0.05 \mathrm{ml}$ de producto, con un total para los dos surcos de $0.3 \mathrm{ml}$ si realizamos 3 pilares a cada lado. Como ya hemos dicho, este procedimiento sería similar al realizado en la construcción de edificios cuando se colocan los pilotes o pilares popularmente conocidos como 'pie de amigo', utilizados para apoyar las repisas. Con la técnica de pilares nuestro objetivo es realizar un relleno, pero también a la vez una sustentación física de la arruga, pliegue o surco.

Comenzamos siempre la confección de los pilares en la región superior del surco nasogeniano, con la aguja en la dermis y con el bisel hacia arriba, perpendicularmente al surco, por retroinyección y de forma bilateral.

La cantidad total de producto a utilizar siempre va a depender de la profundidad del surco a tratar. En nuestra experiencia, utilizamos 1 jeringa de $1 \mathrm{ml}$ en un paciente con surcos moderados, cantidad con la que conseguimos tratar SNG, CMS y reborde labial. Cuando necesita más de $1 \mathrm{ml}$ en una misma región, recomendamos aplicar el resto del producto después de 8 a 10 días, pues con este tipo de compuesto (AH) el edema se presenta muy rápido. Existen excepciones como en el caso de surcos graves y largos, donde es necesario aplicar más de $1 \mathrm{ml}$, pero recomendamos no aplicar mas de $2 \mathrm{ml}$ en total por paciente, evitando asi pérdidas o colocar el producto en regiones no necesarias debido al edema que puede enmascarar temporalmente el resultado. Si fuera necesario, realizaremos otra sesión.

La dermis es una estructura anatómica milimétrica, por lo cual técnicamente no debería ser sobrecargada colocando cantidades abundantes de producto, pues éste se perdería dirigiéndose al subcutáneo. El exceso de material aplicado en un área menor como la dermis, lleva a resultados insatisfactorios (Fig 7). Lo mas importante en un relleno dérmico es la manera y la dirección de colocar el implante. El objetivo del tratamiento será el levantar una región deprimida y no crear un resultado sobrecargado e inestético. Las punciones bilaterales (pilares) perpendiculares al surco nasogeniano, arruga o comisura que sirven de estacas o 'pie de amigo' para la sustentación del mismo, 


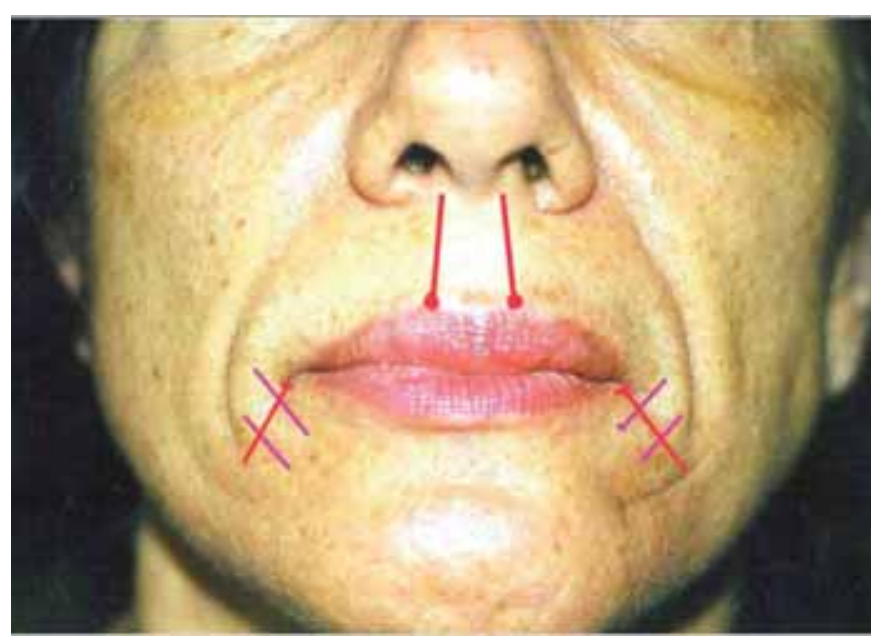

Fig. 8. Esquema de tratamiento de la comisura labial " boca triste" A. Aplicación de AH por retroinyección (líneas rojas) B. Pilares (color lila). C. Tratamiento de los pilares del filtrum, también por retroinyección, dejando al final una cantidad mayor de la que se depositó en el trayecto para dar forma al arco de cupido.

logran nuestro objetivo de levantamiento, soporte y relleno (4-7) de la región a la vez que conseguimos reestructurar el colágeno de la zona debido a las propiedades bioquímicas del ácido hialurónico.

\section{Relleno comisura labial "boca triste"}

Realizamos la maniobra bidigital para verificar el punto de mayor profundidad del pliegue de la comisura bucal e iniciamos la aplicación sobre la zona por retroinyección aplicando una mínima cantidad de producto; luego trazamos igualmente los pilares introduciendo la aguja de fuera hacia dentro y aplicando el ácido hialurónico de dentro hacia fuera. En los casos de "boca triste" colocamos un pilar vertical en la parte externa del labio inferior, como vemos en la Fig. 8.

Generalmente el tratamiento de relleno en el área de la boca debe ser realizado regionalmente, nunca como si fuera una estructura independiente; la boca es una región anatómica desde el punto de vista estético,

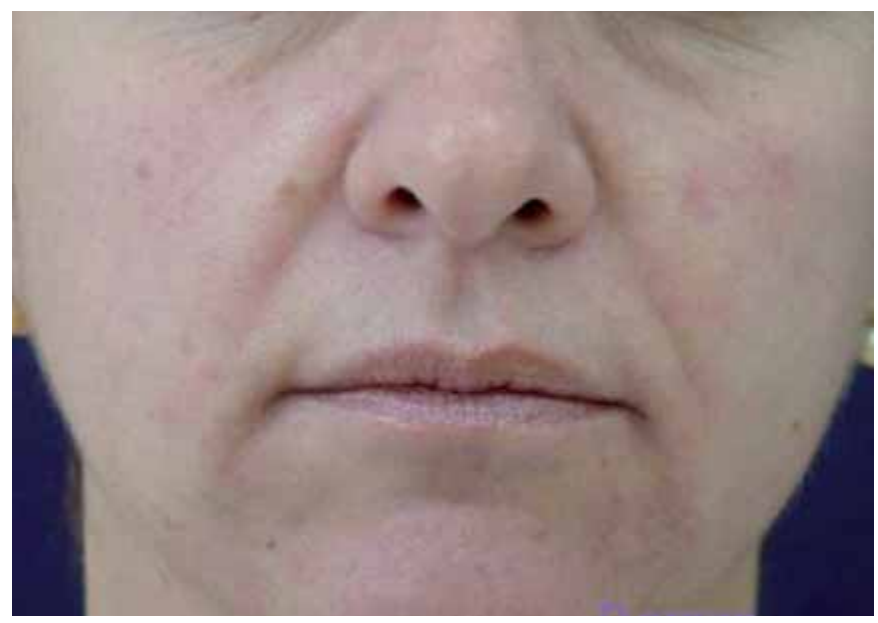

A

Fig. 10. A. Pretratamiento en envejecimiento grado 2 (Glogan). Alteraciones en surcos, comisuras y labios. B. Postratamiento: relleno de Acido Hialurónico, $1 \mathrm{ml}$ en Surco Nasogeniano+Comisura labial, Técnica de pilares. Dos sesiones con intervalos de 12 meses. Imagen tomada a los 24 meses.

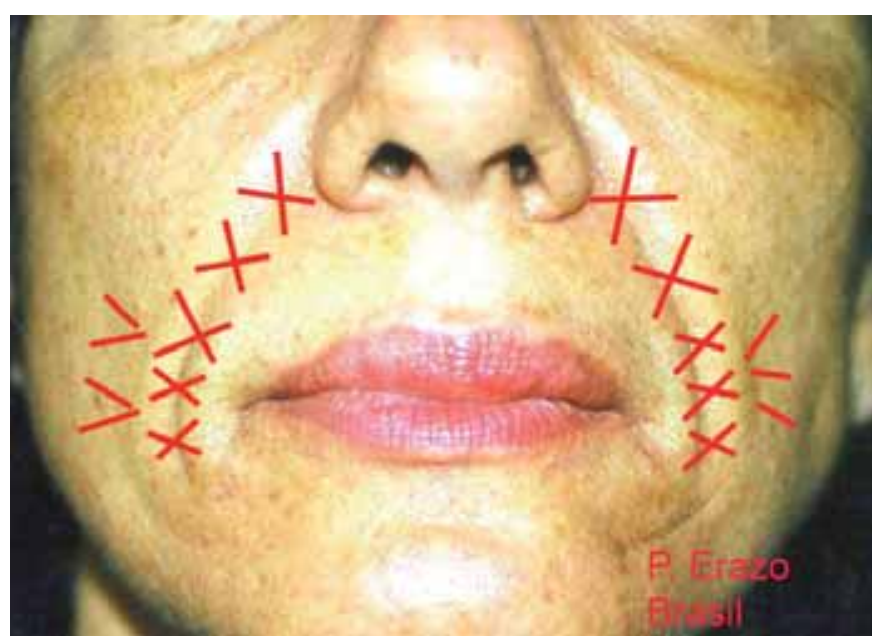

Fig. 9. Esquema de la aplicación del ácido hialurónico en surcos profundos.

por lo que debemos corregir en conjunto las alteraciones que el envejecimiento produce sobre ella: aplanamiento y aumento de la longitud de la boca, disminución del grosor de los labios, presencia de arrugas verticales, comisura labial prominente, etc. (Fig. 9).

\section{Técnica de malla de sustentación}

La malla de sustentación está indicada especialmente:

- Para pacientes del sexo masculino que generalmente tienen surcos más profundos y piel gruesa,

- Para pacientes con surcos profundos e irregulares y en forma de "Y" (4-7) por la unión del surco nasogeniano (SNG) con la comisura labial (CMS).

-Flacidez facial del tercio medio, incluyendo la región malar, en pacientes que no desean realizar cirugía.

La técnica en malla consiste en realizar varios pilares en sentido de dentro hacia afuera formando una $\mathrm{X}$ en toda la longitud del surco o arruga, en las uniones de los surcos y comisuras o en arrugas irregulares (Fig. 10). Logramos así una mayor sustentación de la

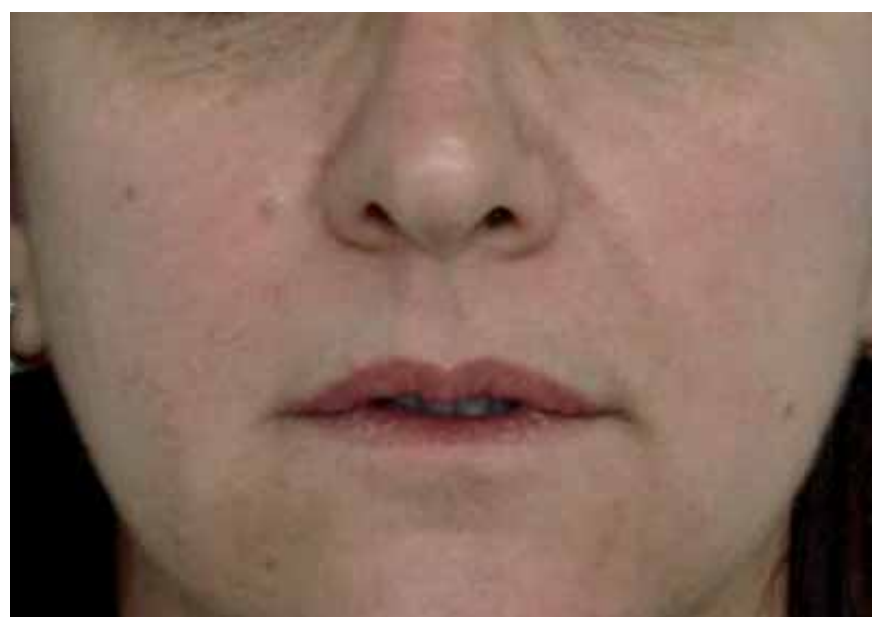

B 


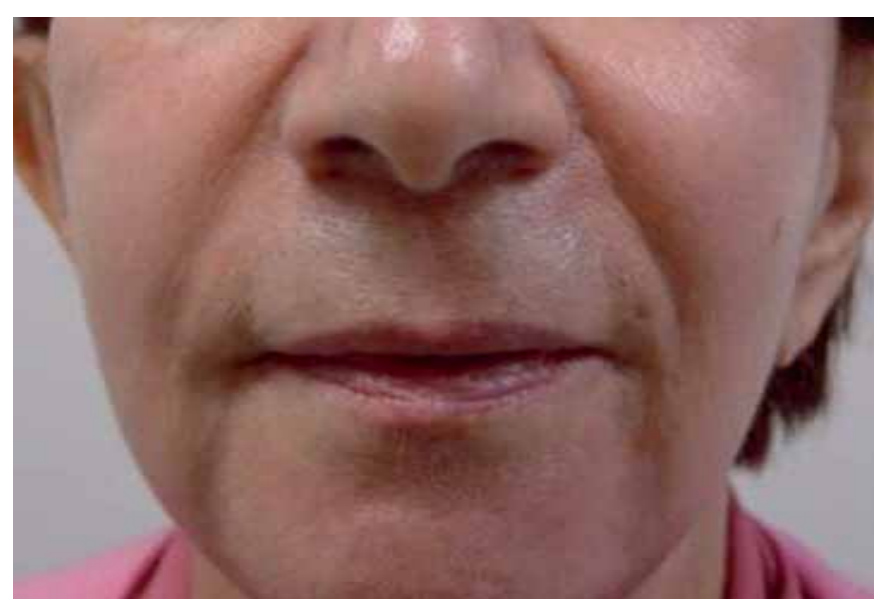

A

Fig. 11. A. Pretratamiento en paciente de 72 años con envejecimiento grado 2-3 (Glogan). Surcos nasogenianos profundos y comisuras marcadas. Arrugas complejas en Y. B. Postratamiento a los 11 meses con $1 \mathrm{ml}$ de Acido Hialurónico.

zona a tratar empleando la misma cantidad de producto que en la técnica anterior. Verificamos clínicamente que cada depósito de AH va a nutrir aproximadamente 1 a $2 \mathrm{~cm}^{2}$ de piel; proporciona buenos resultados utilizando menor cantidad de producto.

Esta técnica resulta también útil en pacientes que presentan surcos complejos, con piel fina elastósica, consiguiendo una revitalización y sustentación de los tejidos sin presentar estigma de relleno por acumulación de producto en una misma región, con apariencia no natural y alteración del perfil facial del paciente.

\section{Resultados}

Mediante el empleo de las técnicas descritas, hemos conseguido resultados estéticos satisfactorios en los pacientes tratados. Empleamos estas técnicas desde principios del año 2000, con una amplia casuística que recoge la aplicación de aproximadamente 2500 jeringas de $1 \mathrm{ml}$. Utilizamos generalmente entre 0.6 a $1,0 \mathrm{ml}$ de solución de Acido hialurónico por

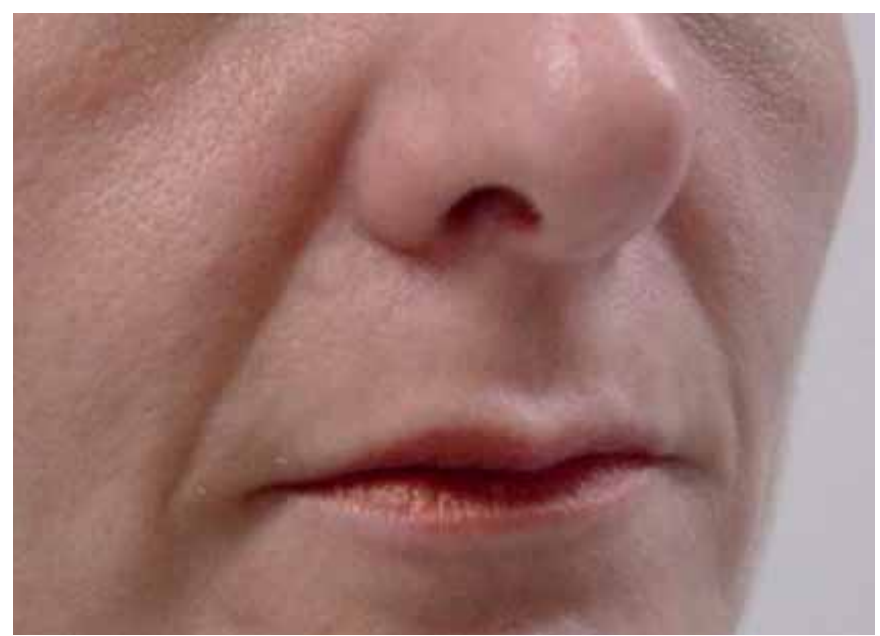

A

Fig. 12. A. Pretratamiento en paciente de 47 años. Técnica de pilares en SNG + CMS labial + relleno reborde labial (bermellón) superior e inferior ( $1 \mathrm{ml}$ Perfectha $\left.{ }^{\circledR}\right)$. B. Postratamiento a los 4 meses demostrando la diferencia de la piel y la mejoría del surco y de la comisura. paciente. En nuestra estadística, en el $80 \%$ de los pacientes utilizamos $1 \mathrm{ml}$ para un tratamiento satisfactorio, retornando para una nueva aplicación después de 8 a 12 meses, verificando en este porcentaje de pacientes que a los 24 ó 36 meses el surco o arruga no vuelven a tener la misma profundidad que al inicio del tratamiento.

Pensamos por lo tanto que con las técnicas descritas, la economía de la cantidad del producto está relacionada directamente por la manera de inyectar el compuesto. (Fig. 11-16).

\section{Discusión}

En las técnicas de rejuvenecimiento facial empleando materiales de relleno, es fundamental realizar una buena evaluación clínica para conseguir una correcta indicación de la técnica y del material a emplear y obtener un resultado estético favorable.

Recomendamos realizar una evaluación del tipo de piel de acuerdo con la tabla de Fitzpatrick y analizar el

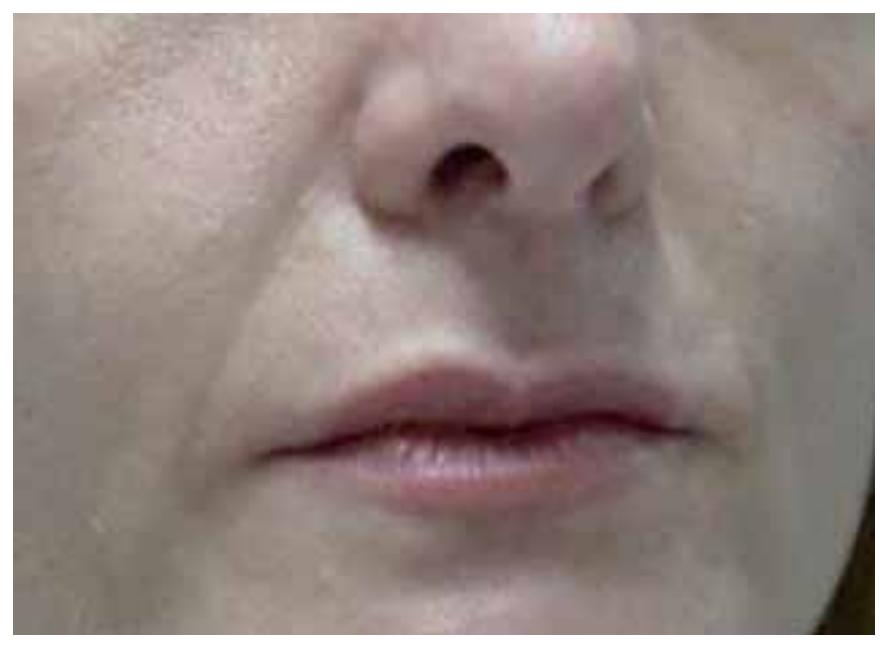

B 


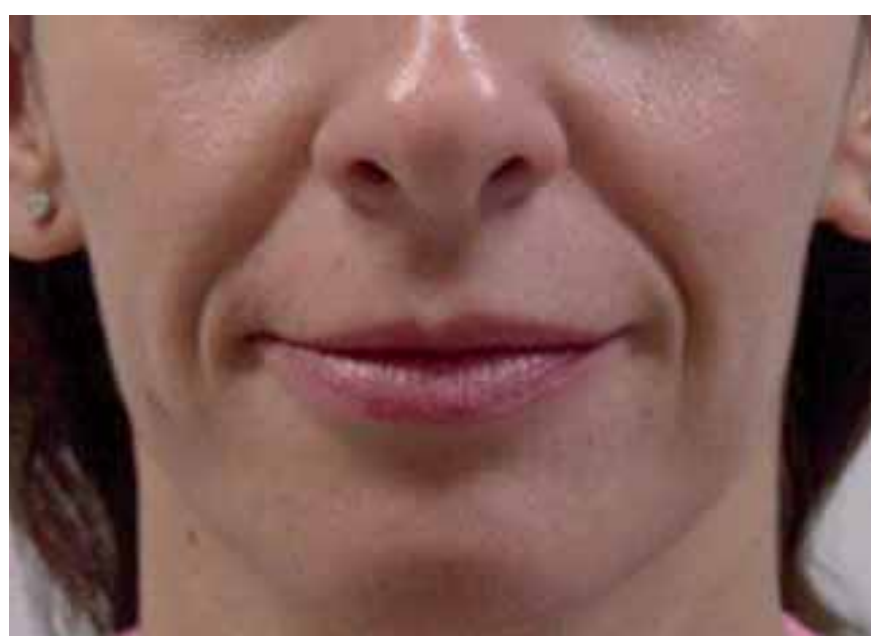

A

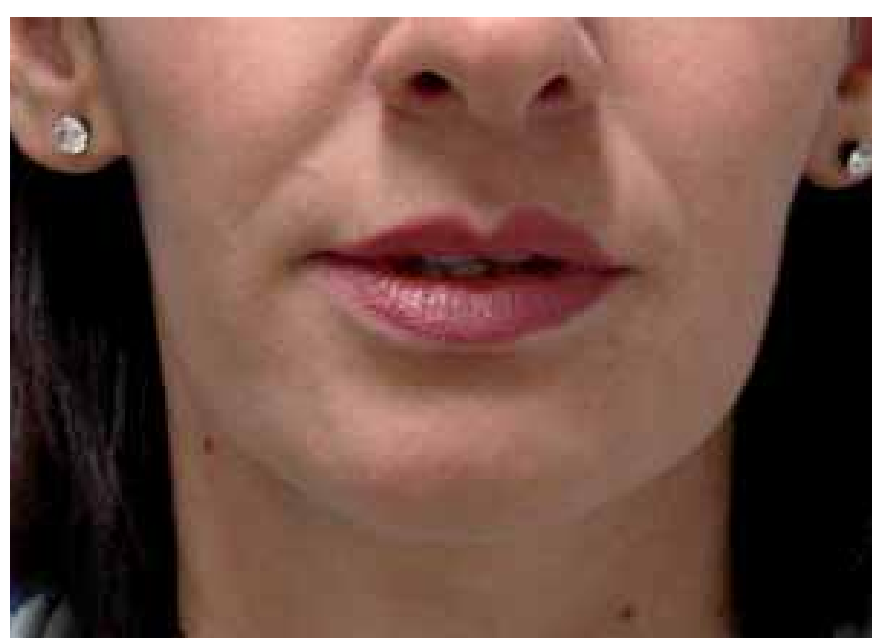

B

Fig. 13. A. Paciente de 40 años con surco nasogeniano profundo y flacidez. B. Postratamiento a los 4 meses con Acido Hialurónico 1 ml con técnica de pilares.

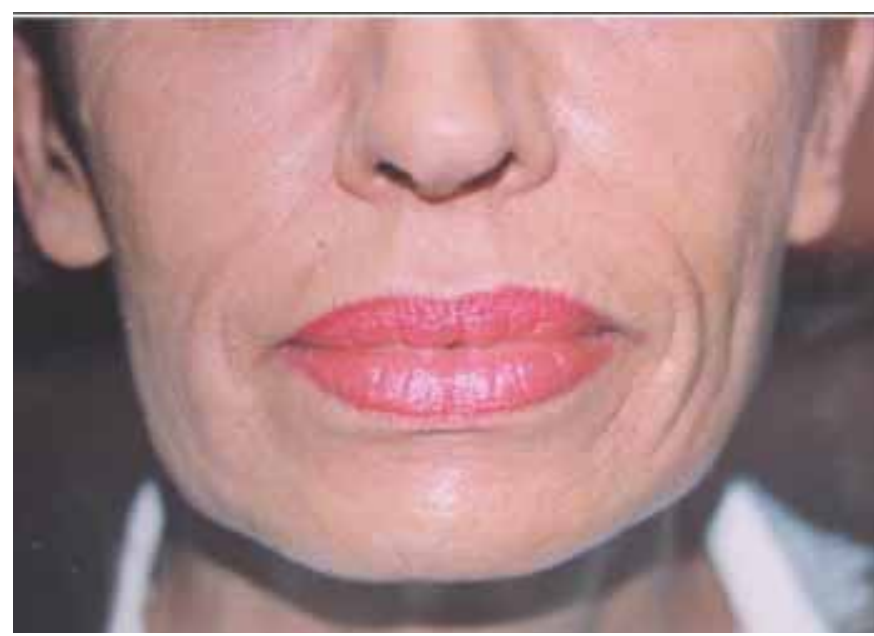

A

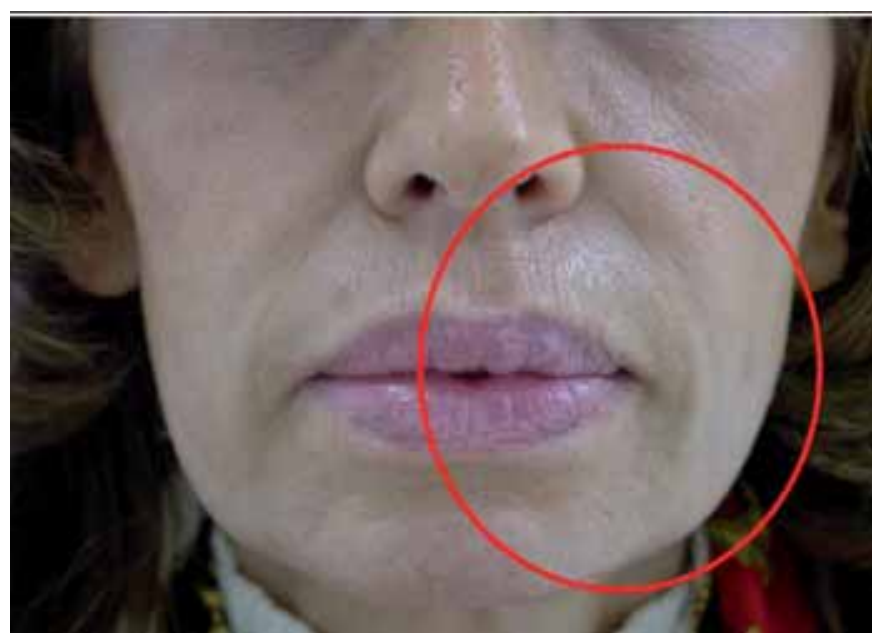

C

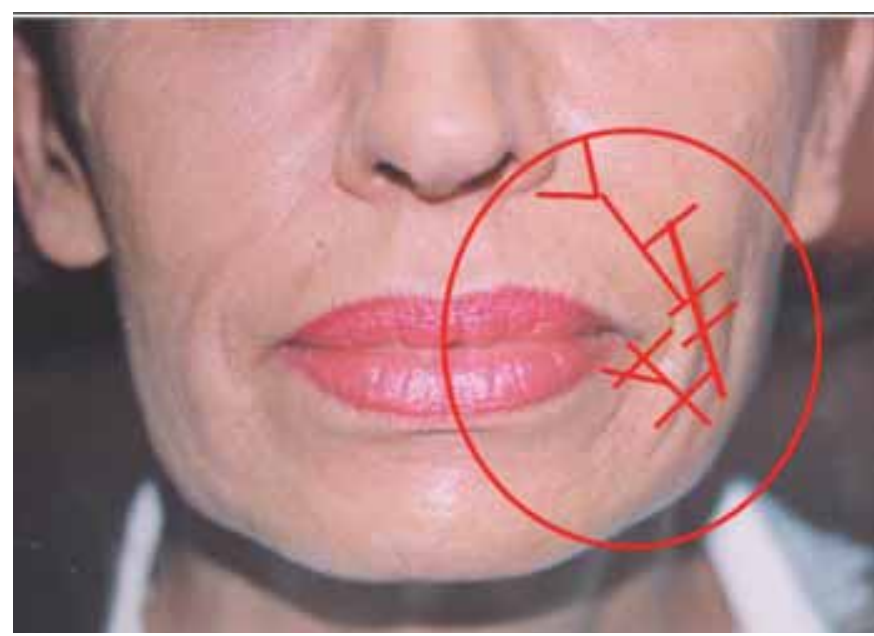

B

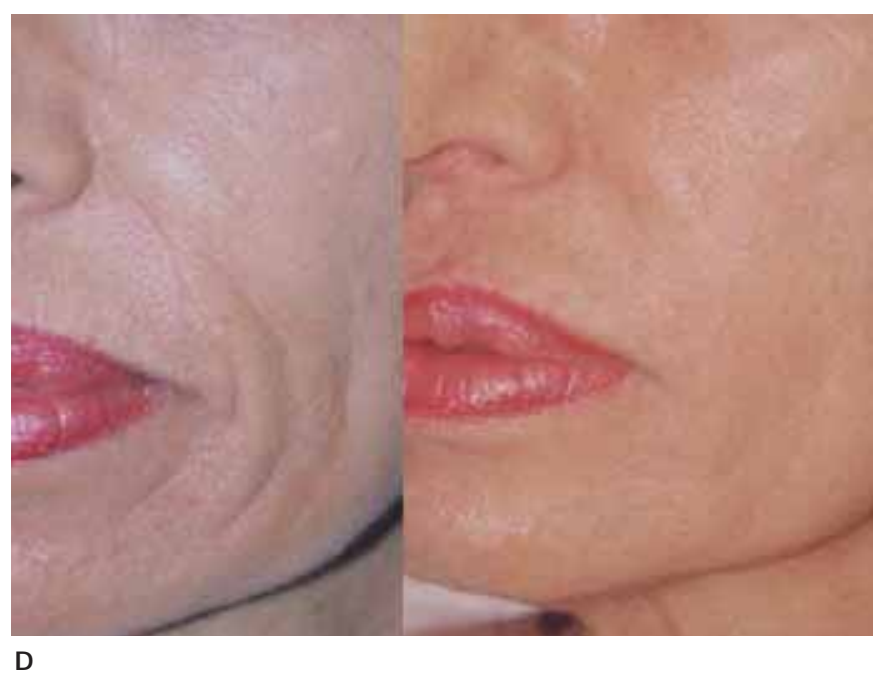

Fig. 14. A. Paciente de 65 años con envejecimiento grado 3. Surco nasogeniano profundo + elastosis bilateral formando una arruga completa que se junta con la comisura labial formando una Y. B. Esquema del tratamiento a realizar con Acido Hialurónico y técnica de pilares. C. Resultado a los 12 meses del tratamiento. D. Vista oblicua en la que se muestra la alteración en surco y comisura, con flacidez y depresión y el resultado 24 meses después del tratamiento (2 sesiones con intervalo de 12 meses).

grado de envejecimiento según la clasificación de Glogau. Sugerimos que al analizar el grado de envejecimiento, éste se relacione directamente con las alteraciones que presente cada individuo y no con su edad.
La principal zona de tratamiento es la que corresponde a los SNG y el material más empleado es el $\mathrm{AH}$, con el que logramos buenos y duraderos resultados cuando se aplica a nivel de dermis. 


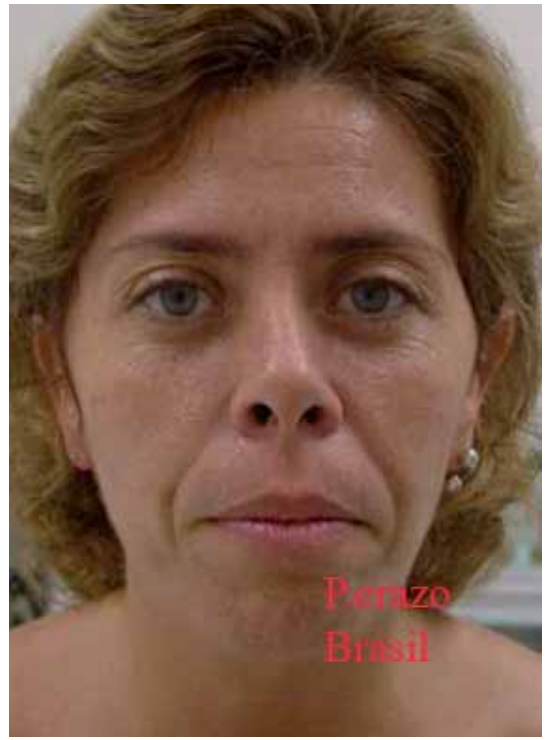

A

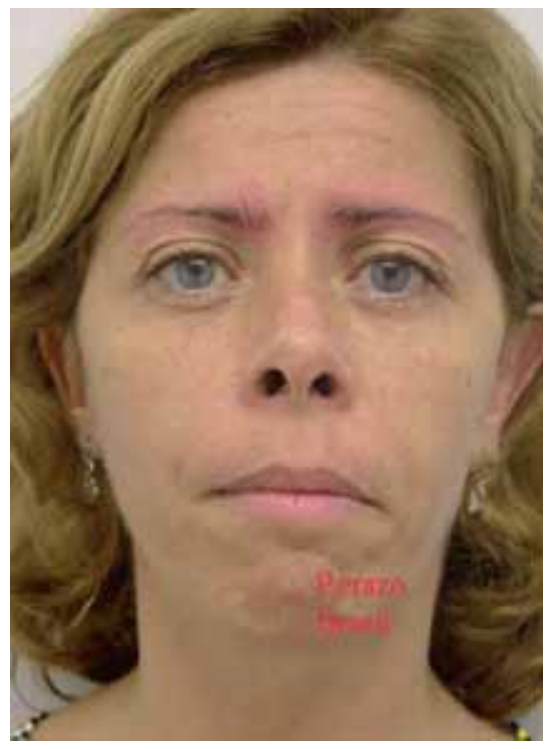

C

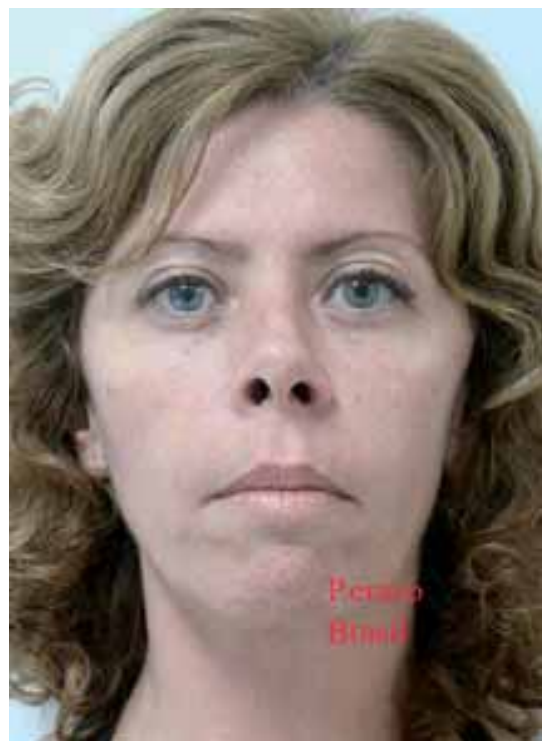

$\mathbf{E}$

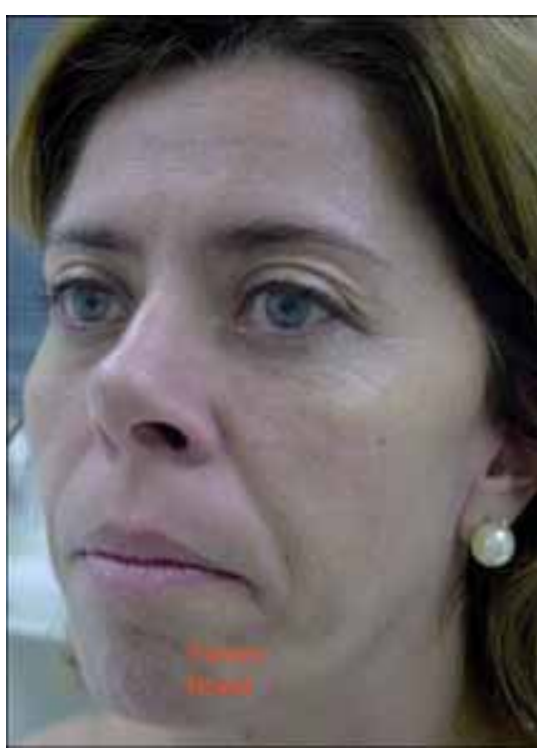

B

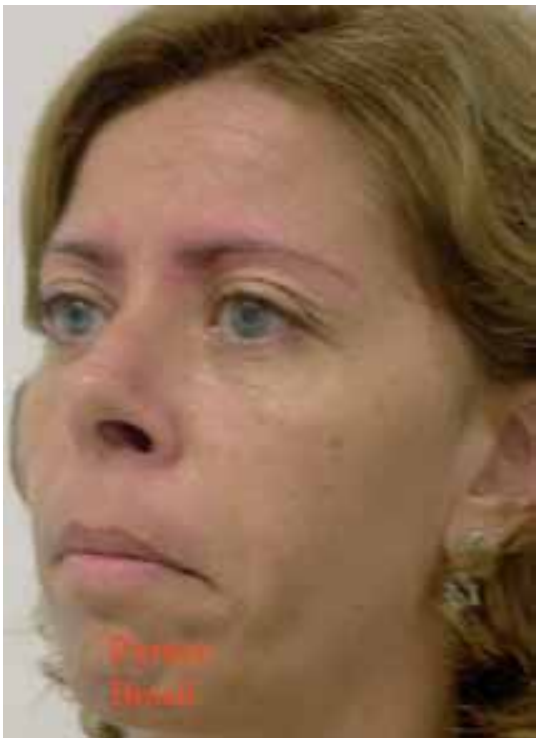

D

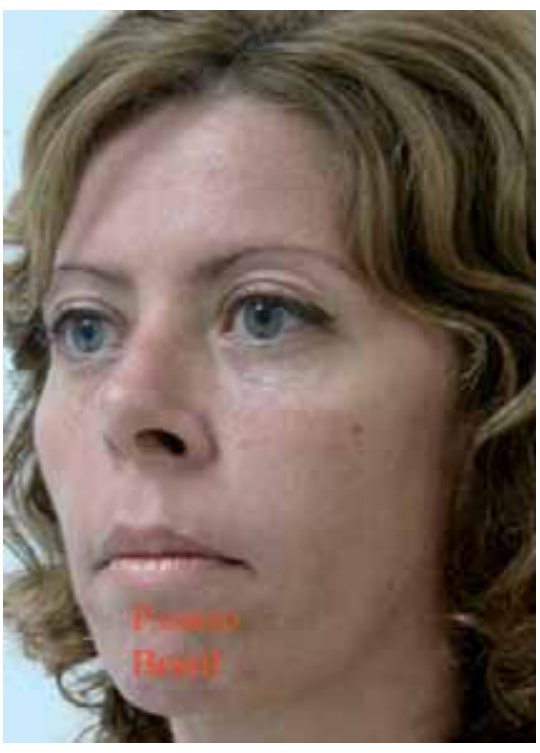

$\mathbf{F}$
Fig. 15. A y B. Paciente de 42 años con envejecimiento grado 2. Se programa tratamiento con relleno con AH (Perfectha ${ }^{\circledR}$ ) en SNG+CMS. C y D. Imagen a los $\mathbf{1 2}$ meses de tratamiento y antes de un segundo relleno en las mismas áreas. Se inician también cuidados específicos de la piel con Acido Mandélico tópico, Myolift (tensor con Argeriline + Densiskin) y sesiones de Gas carbónico. E y F. Imagen a los 24 meses post ratamiento general.

Recomendamos aplicar en una misma región anatómica $1 \mathrm{ml}$, máximo 2 ml. En el 80\% de los pacientes suele ser suficiente emplear $1 \mathrm{ml}$ de producto. Si fuera necesario más producto, realizaremos un refuerzo en otra sesión de tratamiento, pues debido a las características anatómicas de la dermis y a la facilidad que tiene el AH de unirse al agua, es muy frecuente la aparición rápida de edema que impide la mayoría de las veces evaluar nuevamente la región durante la sesión de infiltración, por lo que podríamos perder el parámetro anatómico de referencia y sobrecorregir o corregir defectuosamente.

Cuando el AH es aplicado en la hipodermis, el resultado de elevación de la arruga o surco es mínimo y son necesarias cantidades mayores de producto puesto que el relleno se dirige a la profundidad y no a la superficie. Además, este plano contiene menor cantidad de agua, por lo que el $\mathrm{AH}$ se reabsorbe más rápidamente y por tanto, la técnica falla

Cuando el $\mathrm{AH}$ es aplicado muy superficialmente, puede producir irregularidades o necrosis de la epidermis con extrusión del material. Creemos que esto solamente puede suceder cuando el profesional no está familiarizado con las técnicas de inclusión dérmica, pues es mucho más fácil realizar una inclusión en el subcutáneo, el cual no se produce resistencia, al contrario que en la dermis, donde existe mayor resistencia al inyectar. Las irregularidades producidas por las inclusiones muy superficiales de AH pueden corregirse masajeando la zona durante las primeras 2 semanas. 


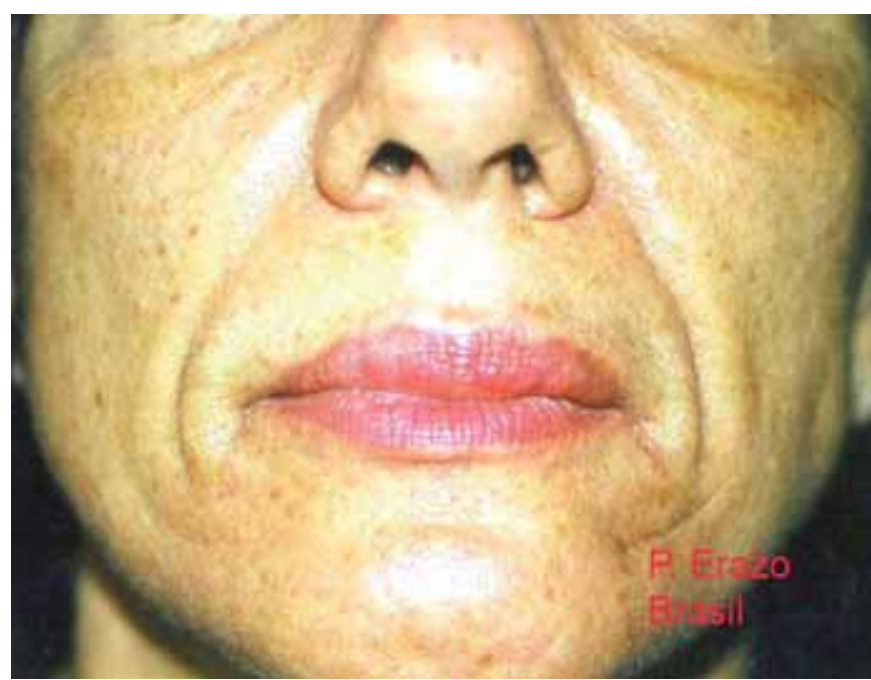

A

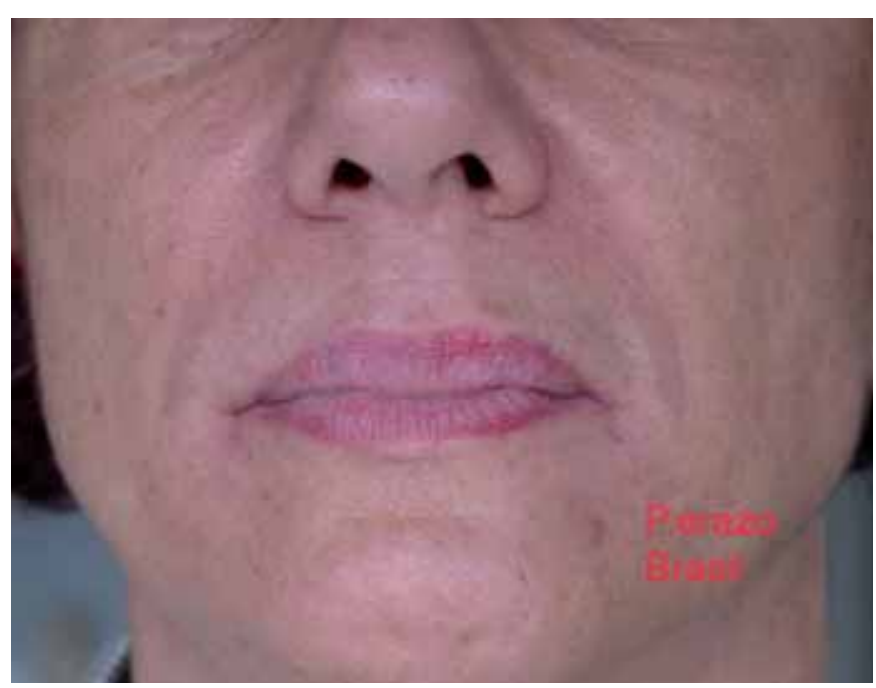

B

Fig. 16. A. Paciente con envejecimiento grado 3. Aplicación de acido Hialurónico con técnica de pilares en SNG + CMS + Filtrum, utilizando 1ml de producto. B. Postratamiento a los 12 meses: mejoría de la piel en surco, labio superior, inferior y naturalidad de la unión entre SNG y comisura labial donde existía flacidez importante.

La mayoría de las complicaciones que se atribuyen al AH, están relacionadas con la mala técnica de inyección.

Cuando se emplean materiales de relleno, el médico debe tener seguridad en la indicación y la cantidad de producto que va a ser administrado, pues el costo final del tratamiento puede no estar dentro de las posibilidades económicas del paciente. Las técnicas que describimos valoran la economía del material y como consecuencia pueden prever un menor precio.

Dentro de nuestras indicaciones, no recomendamos emplear compuestos permanentes debido a las frecuentes complicaciones que presentan y especialmente a la fibrosis progresiva que este tipo de compuestos producen con la consecuente alteración y disminución en la movilidad de la región. Hacemos énfasis en que deben ser respetados los músculos de la mímica facial y en que la región glabelar debe ser considerada anatómicamente como un área de gran peligro donde el incluir compuestos permanentes (no biodegradables) o cualquier sustancia sin los debidos cuidados, puede llegar a que alcancen vasos o venas del globo ocular produciendo alteraciones de la visión e incluso ceguera (6-8) por obstrucción de arterias ciliares cortas, ramas de la arteria oftálmica $(11,13)$.

Los compuestos permanentes o semipermanentes tienen la propiedad de ser aplicados en profundidad.

Los materiales de relleno, cuando se infiltran, deben cumplir la función de rellenar revitalizar y sustentar la piel, permitiendo que continúen los procesos metabólicos de ésta sin obstruirla, cumpliendo con el concepto de rejuvenecimiento (4-8).

\section{Conclusiones}

Siempre observamos que la física y la ley de la gravedad hacen que muchos profesionales del área de la ingeniería civil desarrollen métodos de sustentación muy eficientes que garantizan la seguridad de las construcciones. En Medicina, el médico tiene como objetivo ofrecer seguridad y eficacia en los casos de empleo de materiales de relleno, principalmente utilizar compuestos que faciliten la nutrición y los cambios metabólicos, devolviendo lo que la piel envejecida perdió sin interferir en su fisiología, proporcionando salud a la piel (4-7). Intentamos así de una manera objetiva y no invasiva, bloquear la fuerza de la gravedad y sustentar de manera técnica lo que el envejecimiento altera, dando más importancia a la manera de aplicar que a la cantidad aplicada (5).

\section{Dirección del autor}

Dra. Patricia J. Erazo

Av Ana Costa 221 Conj 22

CEP 11060-001

Santos- Sao Paulo- Brasil

e-mail: p.erazo@uol.com.br

\section{Bibliografía}

1. K Tomihata and Y Ikada: "Cross-Linking of Hyaluronic Acid with Water-Soluble Carbodiimide: "Journal of Biomedical Materials Research 1997, 37: 243-25.

2. EA Balazs et al.: "Hyaluronan Biomaterials: Medical Applications," in Handbook of Biomaterials and Applications, ed. DL Wise et al. (New York: Marcel Dekker, 1995, Pp: 2719-2741. 
3. Erazo P.J; Regazzini D V.: “Acido Hialurônico Injetável : Preenchimento Facial com Acido Hialurônico - Técnica dos Pilares " em Cosmiatria A Ciência da Beleza , Revinter 2004 Perssonelle J, capitulo 10, Pp: 137-143.

4. Erazo P.J; Regazzini DV.; Carvalho A C.: "Preenchimento Facial Com Acido Hialuronico: "Técnica dos Pilares e Malha de Sustentação". Em Procedimentos Estéticos Minimamente Invasivos, Livraria Editora Santos 2005 Yamaguchi Ch, capitulo 38, Pp: 285-295

5. Erazo P.J, de Carvalho A.C.: "Facial Filler with Hialuronic Acid: Pillar Technique and Supporting Mesh". IPRAS 2007 Berlin.

6. Erazo P.J, de Carvalho A.C; Alexander T.: "Relleno Facial con Acido Hialuronico:Tecnica de Pilares y malla de sustentación" en Anales del Congresso FILACP, Quito-Ecuador, 2008.

7. Erazo P.J; Carvalho A.C.: "Implantes Faciais Interesse a Cirurgia Plástica em Atualização em Cirurgia Plástica Estetica e reconstrutiva", Robe editorial 2006 Stocchero I N, Tourneux AAB Capitulo 42, Pp: 383-393

8. Erazo P.J; Carvalho A.C; Vianna P.: "Preenchimento Facial "Tecnica de Pilares e malha de sustentação utilizando Acido Hialuronico" em Atualização em Cirurgia Plástica Estetica e reconstrutiva, Robe editorial 2006 Stocchero I N, Tourneux AAB Capitulo 44, Pp: 401-408.

9. Erazo P.J; Carvalho A.C; Vianna P.: "Revitalizadores Faciais como Terapia Antienvelhecimento" em Atualização em Cirurgia Plástica Estetica e reconstrutiva, Robe editorial 2006 Stocchero I N, Tourneux AAB, Pp: 415-416.

10. Manuell Lee, G. R.: "Mesoplastia facial: escultura facial mini- invasiva progresiva. Reestructuración cutánea como técnica antienvejecimiento". Cir. plást. iberolatinoam. 2008, 34 (1): 41.

11. Erazo, P. J: "Preenchimento Facial com Acido Hialurônico: Técnica dos Pilares" em Anais do XXXVIII congresso Brasileiro de Cirurgia Plástica -Curso Internacional Avançado (2001)TL 18-03.

12. Murata Celina et al: "Cegueira Unilateral: Complicação secundaria a Polimetilmetacrilato em procedimento de cirurgia estéticarelato de dois casos". Rev. Brás. Oftal. 2002; 61 (6): 454.

13. Minami E.: "Complicação com Aquamid®" En :Procedimentos Estéticos Minimamente Invasivos, Livraria Editora Santos 2005 Yamaguchi Ch, capitulo 39, Pp: 297- 303.

14. Coiffman, F.: "Alogenosis iatrogénica: Una nueva enfermedad". Cir.plás.iberolatinoam. 2008, 34(1):1.

15. Caim MG.: "Noções Gerais, Veículos, permeação Cutânea e Compatibilidades":em Cosmiatria A Ciência da Beleza , Revinter 2004 , capitulo 3, Pp: 57-74.

16. Perssonelle J.: "Anatomia, Fisiologia e Bioquímica da Pele Normal e do Envelhecimento Cutâneo": em Cosmiatria A Ciência da Beleza , Revinter 2004, capitulo 1, Pp: 3-26.

17. Haddad A.; Regazzini D.V.: "Procedimentos Minimamente Invasivos em Região Perioral": em Procedimentos Estéticos Minimamente Invasivos, Livraria Editora Santos 2005 Yamaguchi Ch, capitulo 32. Pp: 237-246.

18. Maio M.;Naufal R. R.: "Procedimentos Minimamente Invasivos em Região Perioral” : em Procedimentos Estéticos Minimamente Invasivos, Livraria Editora Santos 2005 Yamaguchi Ch, capitulo 6, Pp: $39-44$. 


\section{Comentario al trabajo uRelleno facial con ácido hialurónico: técnica de pilares y malla de sustentación. Principios básicos para obtener una remodelación facialı}

\section{Dr. Gerardo Rafael Manuell Lee Cirujano Plástico, Mexico D.F.}

En primer lugar deseo felicitar a la Dra. Erazo y sus colaboradores por el excelente trabajo realizado , la amplia descripción de su técnica para infiltración "dérmica" y la insistencia en la selección del caso ideal y del producto de relleno "ideal", claro está, evitando por todos los medios dañar la piel a través del manejo de rellenos "permamentes" que ocasionarían como efecto secundario "fibrosis " y todas sus consecuencias.

Considero que los resultados de la aplicación de acido hialurónico son excelentes dependiendo de una depurada técnica, así como de una habilidad adquirida través de la experiencia.

La naturalidad del resultado del área infiltrada y la normalidad de la mímica facial deben ser la norma para la aplicación de cualquier tratamiento que busque un resultado estético, dando volumen como un efecto de "escultura facial mini-invasiva", con creación de "pilares" de soporte y el restablecimiento del contorno que lleve a la región facial hacia una arquitectura más oval, con el objeto de mantener la prominencias y los puntos de luz y sombras ideales en cada región facial.

La tendencia actual es la prevención del daño por envejecimiento a través de múltiples técnicas mini-invasivas que son seguras y eficaces y van desde peeling, láser, radiofrecuencia, IPL, uso de materiales de relleno como el ácido hialurónico, la mesoplastia, la lipoinyección.y la mejora de la nutrición cutánea tanto para retardar como para minimizar algo del daño producido por el envejecimiento cutáneo intrínseco y extrínseco.

Todo lo anterior no sustituye de ninguna manera la opción quirúrgica, que será indispensable en casos de afecciones severas tanto por flacidez, como por falta de volumen.

Coincido con la Dra. Erazo en que, indiscutiblemente, el área con mayor facilidad para ser manejada con esta técnica es el tercio medio facial, en la que el manejo de este recurso es indispensable, evitando procedimiento quirúrgicos sumamente agresivos.

El favorecer la "nutrición" de la dermis y los cambios metabólicos redundará en una piel más joven y más reactiva y con mayor índice de autoreparación.

En cuanto al manejo del surco nasogeniano, nosotros preconiza- mos iniciar desde el ala nasal hacia abajo, creando primero el concepto de columnas tensionales con la aplicación en forma de tetraedro para tensar el SMAS tridimensional, logrando correcciones de volumen en el triangulo infraorbitario con minimización del volumen infiltrado; este concepto puede ser ampliado en el excelente artículo que se valió de la técnica de mesoplastia principalmente, tanto en pacientes no quirúrgicos como en quirúrgicos, y que publicaron en esta misma Revista los Dres. Muñoz del Olmo y Serra Renom, así como en mi propio artículo.

En la actualidad, es imposible pensar que un paciente con un daño severo se maneje con técnicas quirúrgicas sin el empleo de rellenos. El empleo de la biorevitalización (mesoplastia) preoperatoria, transoperatoria o postoperatoria, acorta notablemente el periodo de convalecencia.

La mejoría en los resultados en una piel tratada con biorevitalización (mesoplastia) y rellenos, con el uso de peelings, láser, radiofrecuencia, onda larga, leds, infrarrojos, etc., es muy notable también.

Es por esto que se puede concluir que, cuando el órgano en cuestión se haya metabólica y orgánicamente más apto, responde mejor y los resultados son mejores, más naturales y duraderos.

Posiblemente en un futuro ya no se piense en cirugía sin preparar la piel para cualquier evento quirúrgico o de manejo con lasser o radiofrecuencia, por ejemplo.

Bibliografía

1. Manuell Lee G.R.: "Mesoplastia facial: escultura facial miniinvasiva progresiva. Reestructuración cutánea como técnica antienvejecimiento" Cir.plást. iberolatinoam 2008, 38(1);41.

2. Thioly D. - Bensoussan: "Mesolift a new "soft" approach in rejuvenation techniques Injection treatments in cosmetic surgery". 2009 Asher B Ed informa Health care Pp: 231-38.

3. Asher B.: "Hylauronic Acids. Injections treatments in cosmetic surgery" 2009 Asher B ed Informa Hetlth care Pp: 263-73

4. Muñoz del Olmo J., Serra Renom J.: "Rejuvenecimiento Periorbitario no invasivo". Cir. plást. Iberolatinoam. 2008, 38(1);11.

\section{Respuesta al comentario del Dr. Rafael Manuell Lee}

\section{Dra. Patricia Erazo}

Agradezco al Dr. Gerardo Manuel Lee los comentarios y esperamos haber contribuido de manera especial en la selección del paciente para tratamiento con métodos mínimamente invasivos, así como para el uso del materiales de relleno que definitivamente nos auxilian en el proceso de tratamiento del envejecimiento, intentando minimizar sus signos, sin caer en la agresividad o anormalidad que dejan ciertos tratamientos, sobre todo cuando se usan productos permanentes. Como el nombre lo dice, "permanentes", así son en la gran mayoría de las veces sus complicaciones. La técnica de pilares y malla de sustentación tiene el objetivo no solamente de relleno, sino también de revitalización cutánea, intentando mejorar especialmente los puntos críticos de envejecimiento. En la actualidad no podemos dejar de lado los tratamientos dirigidos a la región cutánea y muscular superficial, pues el tiempo nos demuestra que a largo plazo nuestros resultados quirúrgicos son mejores cuando complementamos con este tipo de tratamientos, como bien dice el Dr Manuell Lee. 